\title{
Field uptake rates of hydrophobic organic contaminants by semipermeable membrane devices: environmental monitoring considerations
}

\author{
Juan C. Sanchez-Hernandez, ${ }^{a}{ }^{a}$ F. Borghini, ${ }^{b}$ A. Corral ${ }^{a}$ and J. O. Grimalt ${ }^{b}$ \\ ${ }^{a}$ Laboratory of Ecotoxicology, Department of Environmental Science, University of Castilla-La \\ Mancha, 45071 Toledo, Spain. E-mail: juancarlos.sanchez@uclm.es; Fax: +34 925 268840; \\ Tel: +34925268800 \\ ${ }^{b}$ Department of Environmental Chemistry (ICER-CSIC), Jordi Girona 18, 08034-Barcelona, \\ Catalonia, Spain
}

Received 20th April 2004, Accepted 27th August 2004

First published as an Advance Article on the web 21st October 2004

The uptake rates of selected hydrophobic organic contaminants (HOCs) by semipermeable membrane devices (SPMDs) - a polyethylene layflat containing the lipid triolein - were investigated under natural conditions. SPMDs were exposed in three sampling sites (industrial, urban, and agricultural areas) in the Tajo River (Toledo, Spain) for 5, 11 and $20 \mathrm{~d}$. The organochlorine compounds 4,4'-DDT, 4,4'-DDE, $\alpha-\mathrm{HCH}, \gamma-\mathrm{HCH}$, pentachlorobenzene, hexachlorobenzene, and polychlorinated biphenyls (PCBs), and the 16 priority pollutant polycyclic aromatic hydrocarbons (PAHs) were detected in the SPMDs deployed in the three sampling sites. A linear uptake rate was found for DDTs and for 4-Cl- and 5-Cl-substituted PCB congeners in all sampling sites. Concentrations of HCHs $\left(80.3 \mathrm{ng} \mathrm{g}^{-1}\right.$ SPMD for $\alpha-\mathrm{HCH}$ and $109 \mathrm{ng} \mathrm{g}^{-1}$ SPMD for $\gamma-\mathrm{HCH}$ after $20 \mathrm{~d}$ of exposure) increased according to a linear uptake rate in the SPMDs deployed in the sampling site located in the agricultural area. Likewise, a marked increase of total PAH concentration (up to $300 \mathrm{ng} \mathrm{g}^{-1}$ SPMD after $20 \mathrm{~d}$ of exposure) was solely found in the sampling site situated near a thermoelectric power station. Examination of individual PAHs revealed that PAHs with $\log K_{\mathrm{OW}}$ between 4.2 and 5.7 displayed a linear uptake rate over the $20 \mathrm{~d}$ of exposure. Water concentrations (ng L ${ }^{-1}$ ) of HCB (0.80-2.48), lindane (1.30-11.5), 4,4'-DDT (0.61-2.02), 4,4'-DDE (6.89-11.6) and total PAHs (12.0-26.7) estimated by a linear uptake kinetic model were found to be high in comparison with other polluted aquatic systems, and similar to concentrations in other Spanish rivers. Our results suggest that SPMD kinetic uptake studies in the natural environment are recommended for identifying point-pollution sources, and that shorter times of SPMD exposure $(\sim 1$ week $)$ are desirable to minimize one of the main problems of field SPMD deployment, i.e., the biofouling, which negatively affects the estimation of the dissolved HOC concentrations.

\section{Introduction}

Triolein-containing semipermeable membrane devices (SPMDs) - developed by Huckins et al. ${ }^{1}$ - constitute one of the most effective passive methods for sampling hydrophobic organic contaminants (HOCs) in water systems. ${ }^{2,3}$ Many field studies have used SPMDs to investigate the environmental fate of HOCs and to identify point-sources of pollution in both freshwater and marine environments. ${ }^{4,5}$ In others, the accumulation rate of HOCs by SPMDs has been compared to that by aquatic organisms (e.g., mussels), ${ }^{6-9}$ and SPMDs are believed to mimic the bioconcentration process of some HOCs by free-ranging organisms. However, some authors have called into question the use of SPMDs to predict the biological accumulation of HOCs. ${ }^{10,11}$ SPMDs have been also used as pollutant-sequestrating devices for subsequent evaluation of the potential toxicity of the dissolved pollutant fraction using standardized bioassays (e.g., Microtox ${ }^{\mathrm{TM}}$, Mutatox ${ }^{\mathrm{TM}}$, Daphnia toxicity test) ${ }^{12}$ or biomarkers (cytochrome P4501A induction, vitellogenin induction). ${ }^{13}$

One of the most common applications of the SPMD technology is the estimation of dissolved concentrations of HOCs for environmental risk assessment purposes. The water concentration of the analyte of interest is generally estimated from models based on first-order exchange kinetics and equilibrium partitioning concepts. The theoretical basis and experimental evidences of SPMD sampling have been described extensively by others. ${ }^{14-16}$ The linear uptake kinetic model is a frequent approach, which is based on the assumption that the concentration of the contaminant in the lipid phase of the SPMD is linearly related to the sampling time through the equation,

$$
C_{\mathrm{W}}=C_{\mathrm{t}} V_{\mathrm{t}} / R_{\mathrm{S}} t
$$

where $C_{\mathrm{W}}$ and $C_{\mathrm{t}}$ are the concentrations of the analyte in water and triolein, respectively. $V_{\mathrm{t}}$ is the volume of triolein, $t$ is the time of exposure in days, and $R_{\mathrm{S}}$ is the sampling rate for each analyte expressed as the volume of water cleared of analyte per unit time $\left(\mathrm{L} \mathrm{d}^{-1}\right)$.

Eqn. (1) estimates the dissolved concentrations of HOCs considering that the analyte is accumulated by the triolein phase only. However, several studies have demonstrated that an important fraction of chemicals can be accumulated by the polyethylene membrane. ${ }^{17,18}$ If the whole SPMD is analyzed for HOC residues, then the parameters $V_{\mathrm{t}}$ and $C_{\mathrm{t}}$ in eqn. (1) should be substituted by $M_{\mathrm{SPMD}}$ and $C_{\mathrm{SPMD}}$, respectively. ${ }^{19}$ Therefore, the linear uptake model becomes:

$$
C_{\mathrm{W}}=C_{\mathrm{SPMD}} M_{\mathrm{SPMD}} / R_{\mathrm{SC}} t
$$

where $C_{\mathrm{SPMD}}$ is the concentration of the analyte in the whole SPMD (i.e., polyethylene membrane plus triolein), $M_{\mathrm{SPMD}}$ is the mass of the SPMD, and $R_{\mathrm{SC}}$ is the corrected sampling rate for the whole SPMD. The linear uptake model is usually 
applied for estimating dissolved concentrations of high log $K_{\mathrm{OW}}$ (i.e., $\log K_{\mathrm{OW}} \geq 5.0$ ) contaminants from SPMDs exposed for $20-30$ d. ${ }^{15}$ Chemicals with lower $\log K_{\text {Ow }}$ are able to approach an equilibrium during this period of exposure. ${ }^{20}$

Although laboratory studies have investigated the sampling rates for the most common HOCs occurring in water systems, the SPMD uptake rates in natural environments have not been investigated in depth. The aims of this study were: (1) to determine levels of several selected HOCs (i.e., organochlorine pesticides, polychlorinated biphenyls (PCBs), and the 16 priority pollutant PAHs) in SPMDs exposed at three sites in the Tajo River (Spain) and to use the concentrations of organochlorine pesticides and PAHs in SPMDs to estimate the aqueous concentrations for these contaminants; and (2) to examine the uptake rates of HOCs by SPMDs in the natural environment. The Tajo River is partially canalized for agriculture at the Province of Toledo (Region of Castilla-La Mancha, Spain). In addition, a considerable industrial development situated on its banks represents a potential pollution pointsource. There is a growing interest by the Autonomic Government of Castilla-La Mancha in restoring the quality of water of the Tajo River, and in protecting the riverside ecosystems from pollution. In this context, it is necessary to know the level of contamination in the river, to identify point-sources of pollution, and to determine the risk of toxic effects in biota in order to establish guidelines for environmental protection.

\section{Experimental}

\section{SPMD deployment and recovery}

Three sampling sites in the Tajo River (Toledo, Spain) were sampled in July 2001. Sampling site 1 (SS-1) was located $1 \mathrm{~km}$ downstream of a thermoelectric power station, SS-2 was situated $200 \mathrm{~m}$ downstream from the medieval city of Toledo, and the third deployment site (SS-3) was located at a point where the river goes through an agricultural area (Fig. 1).

Standard SPMDs $(81.4 \times 2.5 \mathrm{~cm}$ layflat low density polyethylene tube; $75 \mu \mathrm{m}$ wall thickness) filled with $1 \mathrm{ml}(0.915 \mathrm{~g})$ of triolein (1,2,3-tris[cis-9-octadecenoyl]glycerol, >99\% purity) were acquired from Environmental Sampling Technologies (EST, St. Joseph, MO, USA). Six SPMDs were deployed at each site using deployment devices consisting of a rectangular aluminium screen box $(18 \times 18 \times 21 \mathrm{~cm})$ with a center post for racking two stainless steel SPMD carriers. The deployment devices were 1-2 $\mathrm{m}$ deep in the water column. Two field SPMDs were used as blanks, which were exposed to air during the deployment and recovery operations to check for undesirable contamination during the deployment procedure. In the laboratory, two other SPMDs were used as blanks (non

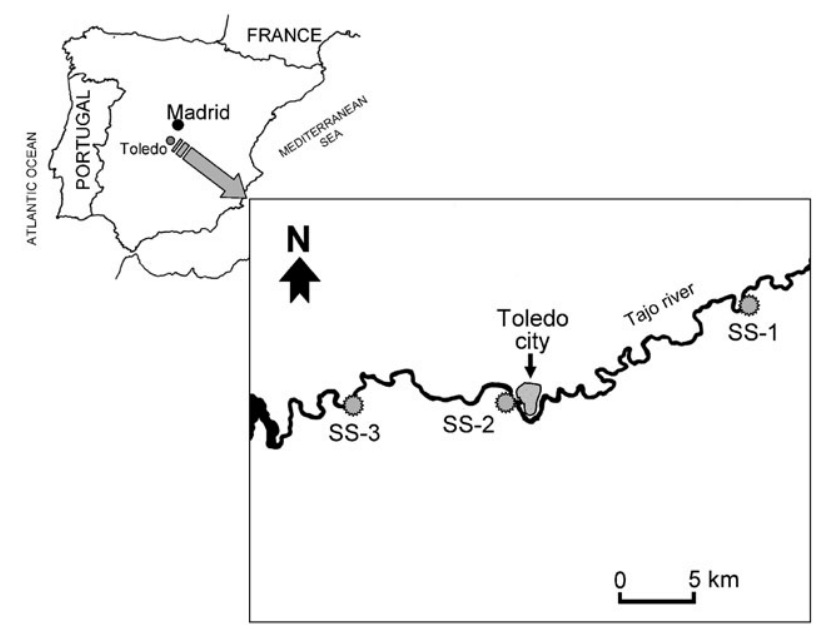

Fig. 1 Location of the sampling sites in the Tajo River (Toledo, Spain). exposed) to check the presence of interference compounds. Two SPMDs per site were recovered at the 5, 11 and $20 \mathrm{~d}$ exposure periods and they were transported to the laboratory in the original canisters kept on ice.

\section{SPMD extraction and analysis}

The external surface of SPMDs was firstly cleaned for removal of surficial periphyton and debris, and then dialyzed in n-hexane ( $c a .125 \mathrm{ml}$ per SPMD) twice for $24 \mathrm{~h}$ in the dark. ${ }^{19}$ The two SPMD extracts from the same sample (applies to each sampling site and survey) were combined to make one sample. The cleanup, fractionation and analytical determination of the SPMD extracts are detailed elsewhere. ${ }^{21,22}$ The extracts were reduced $(\mathrm{ca} .1 \mathrm{ml})$ and then fractionated by column chromatography (35 $\mathrm{mm} \times 0.9 \mathrm{~mm}$ i.d.) using $2 \mathrm{~g}$ of neutral alumina, and $2 \mathrm{~g}$ of sodium sulfate on top. A first organic fraction (F1) containing organochlorine compounds was eluted with $8 \mathrm{ml}$ of n-hexane : dichloromethane $(9: 1, \mathrm{v}: \mathrm{v})$, while a second fraction (F2) containing PAHs was obtained by elution with $10 \mathrm{ml}$ of $\mathrm{n}$-hexane : dichloromethane $(2: 1, \mathrm{v}: \mathrm{v})$. The F1 fraction was subjected to reaction with about $0.5 \mathrm{~g}$ of activated $\mathrm{Cu}$ powder for the removal of sulfur-containing compounds. This fraction was then solvent exchanged into isooctane containing 1,2,3,4-tetrachloronaphthalene and octachloronaphthalene as internal standards (Dr. Ehrenstorfer, Augsburg, Germany). The samples were analyzed with a Hewlett-Packard gas chromatograph (GC) model HP-5890 Series equipped with an electron capture detector (Palo Alto, CA, USA). Organochlorine compounds were quantified by a combination of external standard mixtures (pentachlorobenzene (PeCB), hexachlorobenzene (HCB), $\alpha-\mathrm{HCH}, \gamma-\mathrm{HCH}$, 4,4'-DDE, 4,4'-DDT, and PCB congeners no. 18, 28, 52, 70, $101,105,110,118,123,138,153,158,180,194$ and 199) and the retention index method using $\mathrm{TCN}$ and $\mathrm{OCN}$ as reference compounds. The F2 fraction was hydrolyzed overnight with $20 \mathrm{ml}$ of $6 \% \mathrm{KOH}$ in $\mathrm{MeOH}$ for removal of the aliphatic esters. The neutral fraction was recovered with $n$-hexane $(2 \times 10 \mathrm{ml})$ and cleaned up by adsorption chromatography with $2 \mathrm{~g}$ of neutral aluminium oxide. PAHs were obtained by elution with hexane : dichloromethano $(1: 2, \mathrm{v}: \mathrm{v})$, and the extracts were solvent exchanged to isooctane and anthracene- $\mathrm{d}_{10}\left(\mathrm{~A}-\mathrm{d}_{10}\right)$ was added as internal standard to the vials prior to injection. The PAH fraction was analyzed by GC mass spectrometry, operating in the selected ion monitoring (SIM) and electron impact modes. Quantitative analysis of PAHs was also performed by combination of an external standard (16 priority pollutant PAHs, EPA mix 9, Dr. Ehrenstorfer, Augsburg, Germany) and retention index methods. Molecular ions and base peak ions from each PAH were used for identification and quantification. Concentrations of analytes were expressed as nanograms on a SPMD weight basis.

The quality assurance/quality control procedure used was the same as applied in the intercalibration exercise for the analysis of PCBs in the Global Mass Balance of Semivolatile Organic Compounds project. ${ }^{23}$ Recovery of the analytical procedure was evaluated from surrogate standard data. Before dialysis, the SPMDs were spiked with $10 \mu$ of a standard solution containing the PCB congeners 30 and 209 (IUPAC number) (340 $\mathrm{ng} \mathrm{ml}^{-1}$ and $500 \mathrm{ng} \mathrm{ml}^{-1}$, respectively), and $100 \mu \mathrm{l}$ of the deuterated PAHs benzo(ghi)perylene- $\mathrm{d}_{12}\left(\right.$ BghiP- $\left.\mathrm{d}_{12}\right)$ and benzo(a)pyrene- $\mathrm{d}_{10}\left(\mathrm{BaP}-\mathrm{d}_{10}\right)\left(420 \mathrm{ng} \mathrm{m}^{-1}\right.$ and $400 \mathrm{ng}$ $\mathrm{ml}^{-1}$, respectively) used as surrogate standards. Mean percentage of recovery for BghiP- $\mathrm{d}_{12}$ and $\mathrm{BaP}-\mathrm{d}_{10}$ were 71 and $85 \%$, respectively, whereas the averaged recoveries of the PCB congeners \#30 and \#209 were 74 and 95\%, respectively. Results were not corrected for recovery of these compounds; they were used for checking the efficiency of the extraction and enrichment method. 


\section{Results and discussion}

\section{Organochlorine compounds}

Organochlorine residues were detected in the three sampling sites and concentrations varied between 11.3 and $43.05 \mathrm{ng} \mathrm{g}^{-1}$ SPMD for PeCB, 4.2 and 37.1 for HCB, 14.6 and 80.3 for $\alpha-\mathrm{HCH}, 2.7$ and 109 for $\gamma-\mathrm{HCH}, 13.6$ and 138 for $4,4^{\prime}$-DDE, and between 3.8 and 32.7 for $4,4^{\prime}$-DDT. Concentrations of DDTs displayed a linear accumulation rate in the SPMDs deployed at all sampling sites (Fig. 2). The ratio DDE to DDT ( $>3: 1$ at all deployment sites) could suggest an old use of this insecticide, as has also been concluded by Bordajandi et al. ${ }^{24}$ examining the concentrations of DDT and DDE in fish collected from the River Turia (SE Spain) in February 2000. They also found a high proportion of DDE in the common trout $\left(3.60 \mathrm{ng} \mathrm{g}^{-1}\right.$ wet weight, mean value) and in the European eel $\left(29.9 \mathrm{ng} \mathrm{g}^{-1}\right)$ compared to DDT concentrations $\left(0.44 \mathrm{ng} \mathrm{g}^{-1}\right.$ for the common trout and $7.04 \mathrm{ng} \mathrm{g}^{-1}$ for the European eel). These observations are consistent with the ban of this insecticide in Spain in 1977. However, despite the ban on DDT use, Fernández et al. ${ }^{25}$ found higher 4,4'-DDT concentrations compared to 4,4'-DDE in surficial and ground water samples collected from the Southeast Regional Park in Madrid (Spain) in May 1996. On the other hand, laboratory experiments have evidenced that the sampling rate at $26{ }^{\circ} \mathrm{C}$ for $4,4^{\prime}$-DDE $\left(6.8 \mathrm{~L} \mathrm{~d}^{-1}\right)$ is higher than that for $4,4^{\prime}$-DDT $\left(4.1 \mathrm{~L} \mathrm{~d}^{-1}\right),{ }^{26}$ which might account for higher concentrations of the former in the SPMDs. Conclusive remarks on a current use of DDT based on the DDE : DDT ratio in the SPMDs is therefore risky.

The highest concentrations of HCHs ( $80.3 \mathrm{ng} \mathrm{g}^{-1}$ SPMD for $\alpha-\mathrm{HCH}$ and $109 \mathrm{ng} \mathrm{g}^{-1}$ SPMD for $\gamma-\mathrm{HCH}$ after $20 \mathrm{~d}$ exposure)
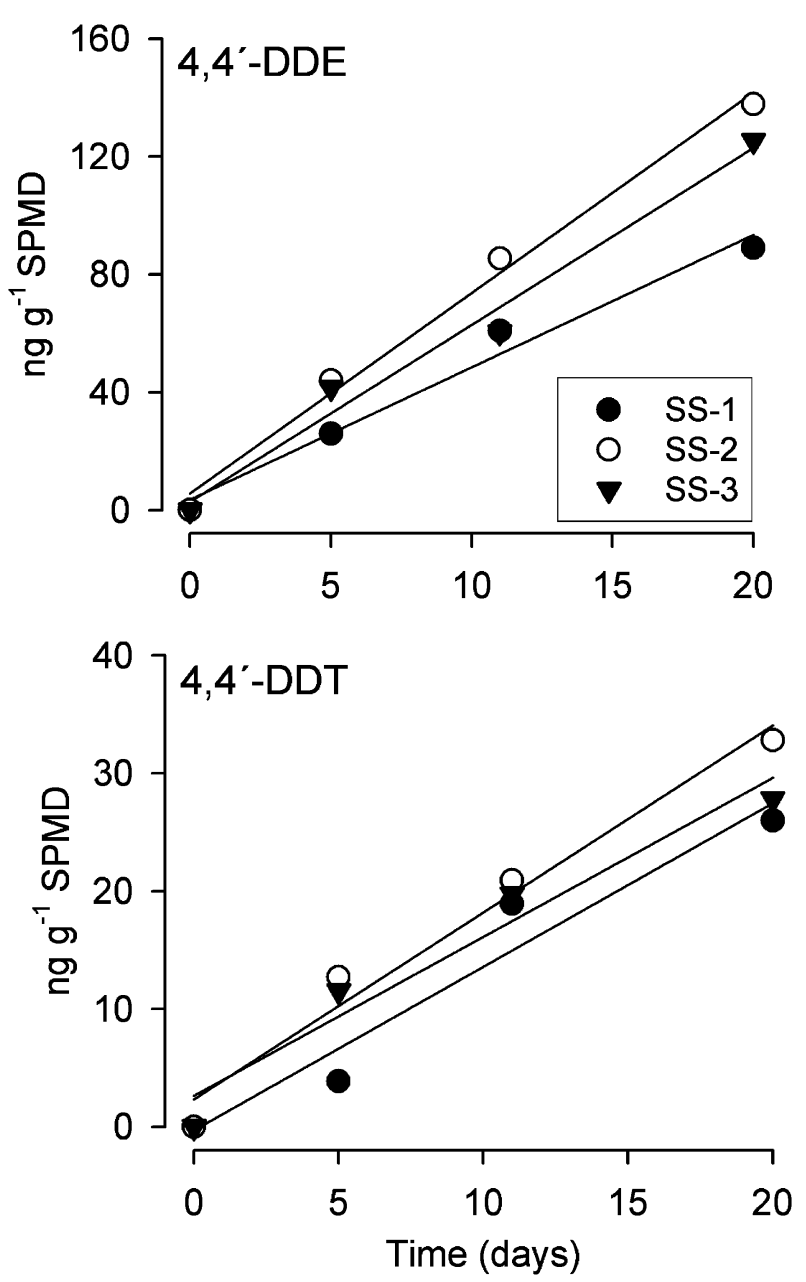

Fig. 2 Uptake rates of DDTs by SPMDs exposed for 5, 11 and $20 \mathrm{~d}$ in the Tajo River. See Fig. 1 for location of the sampling sites (SS). were found in the SPMDs deployed at SS-3 (agricultural area). Moreover, a linear uptake rate was found for both $\mathrm{HCH}$ isomers in the SPMDs exposed at the agricultural sampling site, whilst they seemed to reach equilibrium within the $20 \mathrm{~d}$ exposure period in the SPMDs deployed at the other two sites (Fig. 3). Under these considerations, it could be suggested that lindane is currently in use in that area. Amaral et al. ${ }^{27}$ also suggested an agricultural origin for $\mathrm{HCHs}$ to explain the high concentrations $\left(3.02 \pm 1.65 \mathrm{ng} \mathrm{L}^{-1}\right.$, mean $\left.\pm \mathrm{SD}\right)$ of $\gamma-\mathrm{HCH}$ found in water samples from the Ebre River (Catalonia, Spain) compared to the concentrations of $\alpha-\mathrm{HCH}(0.20 \pm 0.017 \mathrm{ng}$ $\mathrm{L}^{-1}$ ). On the other hand, HOCs with low $\log K_{\mathrm{OW}}$ values tend to reach equilibrium in SPMD more rapidly than those with higher $\log K_{\mathrm{OW}}$ values. ${ }^{19}$ The $\log K_{\mathrm{OW}}$ values for $\gamma-\mathrm{HCH}$ and $\alpha-\mathrm{HCH}$ are 3.71 and $3.86,{ }^{26}$ respectively. This means that $\mathrm{HCHs}$ would reach equilibrium in SPMDs in a short time of exposure unless a current source for these compounds exists. The different pattern of $\mathrm{HCH}$ uptake rates shown in Fig. 3 seems to support this assumption.

The concentrations of organochlorine pesticides measured in the SPMDs deployed in the Tajo River were high in comparison to related studies. Levels of DDTs $\left(0.23-4.0 \mathrm{ng} \mathrm{g}^{-1}\right.$ SPMD for $4,4^{\prime}$-DDE; $<0.1-1.1$ for $4,4^{\prime}$-DDT) and lindane $(0.22-0.51$ $\mathrm{ng} \mathrm{g}^{-1}$ SPMD) measured in SPMDs deployed for $28 \mathrm{~d}$ in the Missouri River - a river flowing through extensive agricultural areas - were considerably lower than those measured in our SPMDs. ${ }^{28}$ Similarly, Ellis et al. ${ }^{29}$ found a concentration range for lindane (0.2-0.7 $\mathrm{ng} \mathrm{g}^{-1}$ SPMD) in SPMDs exposed for $28 \mathrm{~d}$ in the upper Mississippi River, two orders of magnitude lower than those measured in the SPMDs exposed for $20 \mathrm{~d}$ at the SS3 site. Maximum concentrations of DDTs (sum of $p, p^{\prime}$-DDT, $o, p^{\prime}$-DDT, $p, p^{\prime}$-DDE, $o, p^{\prime}$-DDE, $p, p^{\prime}$-DDD and $o, p^{\prime}$-DDD) and $\mathrm{HCHs}$ (sum of $\alpha-\mathrm{HCH}, \gamma-\mathrm{HCH}$ and $\beta-\mathrm{HCH}$ ) of 22 and $20 \mathrm{ng} \mathrm{g}^{-1}$ SPMD, respectively, were measured in SPMDs exposed for 4 weeks in heavily polluted freshwater areas of Amsterdam (The Netherlands). ${ }^{30}$ These organochlorine concentrations were almost one order of magnitude lower than those determined after $20 \mathrm{~d}$ of SPMD exposure in the Tajo River, in spite of the fact that we determined the sum of two isomers of $\mathrm{HCH}$ and the main metabolite of 4,4'-DDT for concentrations of total HCHs and DDTs.

The chlorobenzenes $\mathrm{HCB}$ and $\mathrm{PeCB}$ were recorded at high concentrations in the SPMDs deployed at the SS-3 (34.1-43.05 $\mathrm{ng} \mathrm{g}^{-1}$ SPMD for HCB) and SS-1 (9.8-14.2 $\mathrm{ng} \mathrm{g}^{-1}$ SPMD for $\mathrm{PeCB})$ sites, however a linear uptake rate for these compounds was only observed in the SPMDs exposed in the SS-2 site. The reason for a lack of linear uptake kinetics of $\mathrm{HCB}$ and $\mathrm{PeCB}$ in

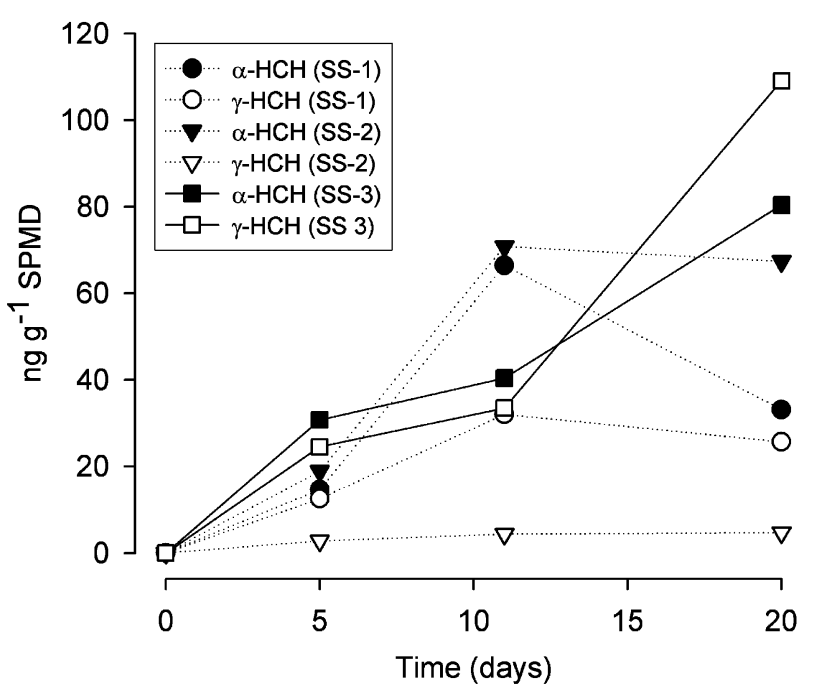

Fig. 3 Uptake rates of the isomers $\alpha$ - and $\gamma$-hexachlorocyclohexane $(\mathrm{HCH})$ by SPMDs exposed for 5, 11 and $20 \mathrm{~d}$ in the Tajo River. 

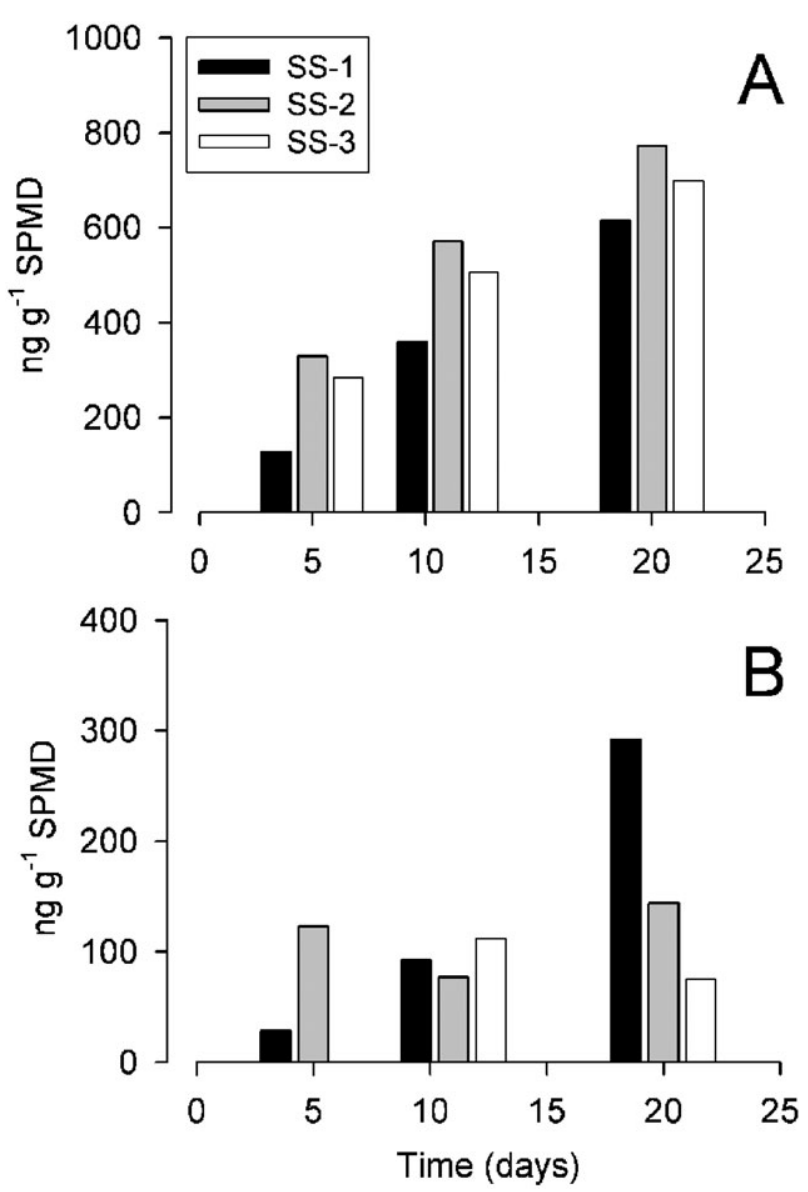

Fig. 4 (A) Temporal variations of concentrations of total PCBs (sum of the congeners IUPAC no. 18, 28, 52, 70, 101, 105, 110, 118, 123, 138, $153,158,180,194$ and 199), and (B) total PAHs (sum of the 16 priority pollutant PAHs) in SPMDs exposed for 5, 11 and $20 \mathrm{~d}$ in the Tajo River.

the SS-1 and SS-3 sites is not clear because these compounds have a $\log K_{\mathrm{OW}}>5$ and would display a similar uptake curve.

Concentrations of the sum of analyzed PCBs increased linearly in the SPMDs as time of exposure increased (Fig. 4A), with a variation range from $128(t=5 \mathrm{~d})$ to $771 \mathrm{ng} \mathrm{g}^{-1}$ SPMD $(t=20 \mathrm{~d})$. These total PCB concentrations were quite similar to those (77 to $790 \mathrm{ng} \mathrm{g}^{-1}$ SPMD) reported for SPMDs exposed for $35 \mathrm{~d}$ in the Saginaw River (Michigan, USA), a heavily contaminated water system. ${ }^{31}$ The field study of Verweij et al. ${ }^{30}$ reported total PCB concentrations varying from 2.1 to $40 \mathrm{ng}$ $\mathrm{g}^{-1}$ SPMD, a concentration range much lower than that determined in our SPMDs. Comparisons of available literature data for water PCB concentrations between Spanish rivers and those from other countries, ${ }^{25}$ support these elevated concentrations of PCBs found in the SPMDs exposed in the Tajo River.

Concentrations of individual PCB congeners followed the same pattern as totals, except for $3 \mathrm{Cl}$-substituted congeners, which seemed to begin to reach a steady state during the $20 \mathrm{~d}$ exposure (Fig. 5). This was not surprising because lower chlorinated PCB congeners, (low $\log K_{\mathrm{OW}}$ ), tend to reach equilibrium in SPMDs before more heavily chlorinated congeners. ${ }^{32}$ Concentrations of the lower chlorinated PCBs (3Cland 4Cl-substituted) in SPMDs exposed for 5 or $11 \mathrm{~d}$ were slightly higher than the other congeners (Fig. 5). This is in agreement with the observations by Echols et al. ${ }^{31}$ and Peven et al., ${ }^{9}$ and it is consistent with the fact that water solubility and molecular size of the PCB congeners could account for differences in the SPMD sampling rates. The higher-chlorinated and less water-soluble PCBs are more likely to be associated with DOC, particulate organic carbon (POC) and/or sediment organic carbon rather than dissolved in water. Furthermore, Huckins et al. ${ }^{14}$ attributed the reduction in sampling rate for higher chlorinated PCB congeners to limitations related to transient pore diameter of the SPMD.

\section{Polycyclic aromatic hydrocarbons}

Almost all 16 priority pollutant PAHs were accumulated in the SPMDs deployed at the three sampling sites (Fig. 4B). The highest individual PAH concentrations in SPMDs were achieved for phenanthrene, anthracene, fluoranthene, pyrene, benzo(a)anthracene, chrysene, benzo(b)fluoranthene, benzo(k)fluoranthene and benzo(a)pyrene, irrespective of the sampling site and time of exposure. At the SS- 2 and SS-3 sites, total PAH concentrations in the SPMDs varied among sampling times, with no apparent linear uptake. It is well accepted that SPMDs are integrative sampling systems of HOCs, ${ }^{3}$ however, loss of analytes such as PAHs can occur when water concentration decreases. Baussant et al. ${ }^{32}$ reported a percentage of PAH elimination from contaminated SPMDs of about $45 \%$ when SPMDs were transferred to clean water for 10 days; the lower molecular weight PAHs being the fastest eliminated. Furthermore, DOC or POC concentrations can contribute to a non-linear uptake rate because PAHs with a $\log K_{\text {OW }}>5$ tend to associate with organic carbon. The temporal variations in PAH concentrations found in the SPMDs deployed at the SS-2 and SS-3 sites (Fig. 4B) could reflect fluctuations either in dissolved PAHs or in organic carbon concentrations.

A linear uptake rate for most PAHs was observed at the SS-1 site, where the thermoelectric power station is situated (Fig. 6). At this site, total PAH concentrations varied from $27.8 \mathrm{ng} \mathrm{g}^{-1}$ SPMD at $t=5 \mathrm{~d}$ to $300 \mathrm{ng} \mathrm{g}^{-1}$ SPMD at $t=20 \mathrm{~d}$, which were much lower than that found, for example, in SPMDs exposed for $28 \mathrm{~d}$ in several polluted aquatic systems in Amsterdam (859-32 $306 \mathrm{ng} \mathrm{g}^{-1}$ SPMD). ${ }^{30}$ In our study, PAHs with a log $K_{\text {Ow }}$ value between 4.2 and 5.7 displayed a marked linear uptake rate. These results are consistent with theory and with many experimental studies. Bennett et $a l^{33}$ and Huckins et al. ${ }^{15}$ found that the SPMD sampling rates increased up to a maximum value for those PAHs with a $\log \mathrm{K}_{\mathrm{OW}}$ of about 5.3. Luellen and Shea ${ }^{20}$ also reported linear uptake rates for PAHs and related heterocyclic hydrocarbons with $\log K_{\mathrm{OW}}$ above 4.5 , the $R_{\mathrm{S}}$ maximum being for PAHs with $\log K_{\text {Ow }}$ between 5.0 and 5.5 , whereas PAHs with lower $K_{\mathrm{OW}}$ reached a steady state during $30 \mathrm{~d}$ of exposure. Amongst the strongest reasons for the reduction of SPMD sampling rate of PAHs with high log $K_{\mathrm{OW}}$ $(>5.5)$, the membrane impedance (pore size of the membrane) and water resistance (aqueous boundary layer) seem to be the most important determinants. ${ }^{14,18}$ However, recently it has been suggested that the aqueous boundary layer does not have significant influence on the uptake of PAHs with $\log$ $K_{\text {OW }}>4.5 .^{20}$

The temporal increase of the PAH concentrations in the SPMDs deployed at the SS-1 site (thermoelectric power station) is probably the result of continuous discharges from a local source. We suggest furthermore that the examination of SPMD uptake rates of individual PAHs can be a more effective approach in the identification of local sources of pollution than making comparisons of total PAH concentrations in SPMDs exposed for long periods of time (e.g., 20-30 d) following a spatial gradient, especially when loss of certain PAHs from SPMDs can take place.

\section{Estimated dissolved concentrations}

One of the main limitations in the estimation of water HOC concentrations derived from SPMDs is the development of a periphyton layer on the exterior surface of the membrane, which can reduce the sampling rate. This problem can be solved by the addition of permeability/performance reference 

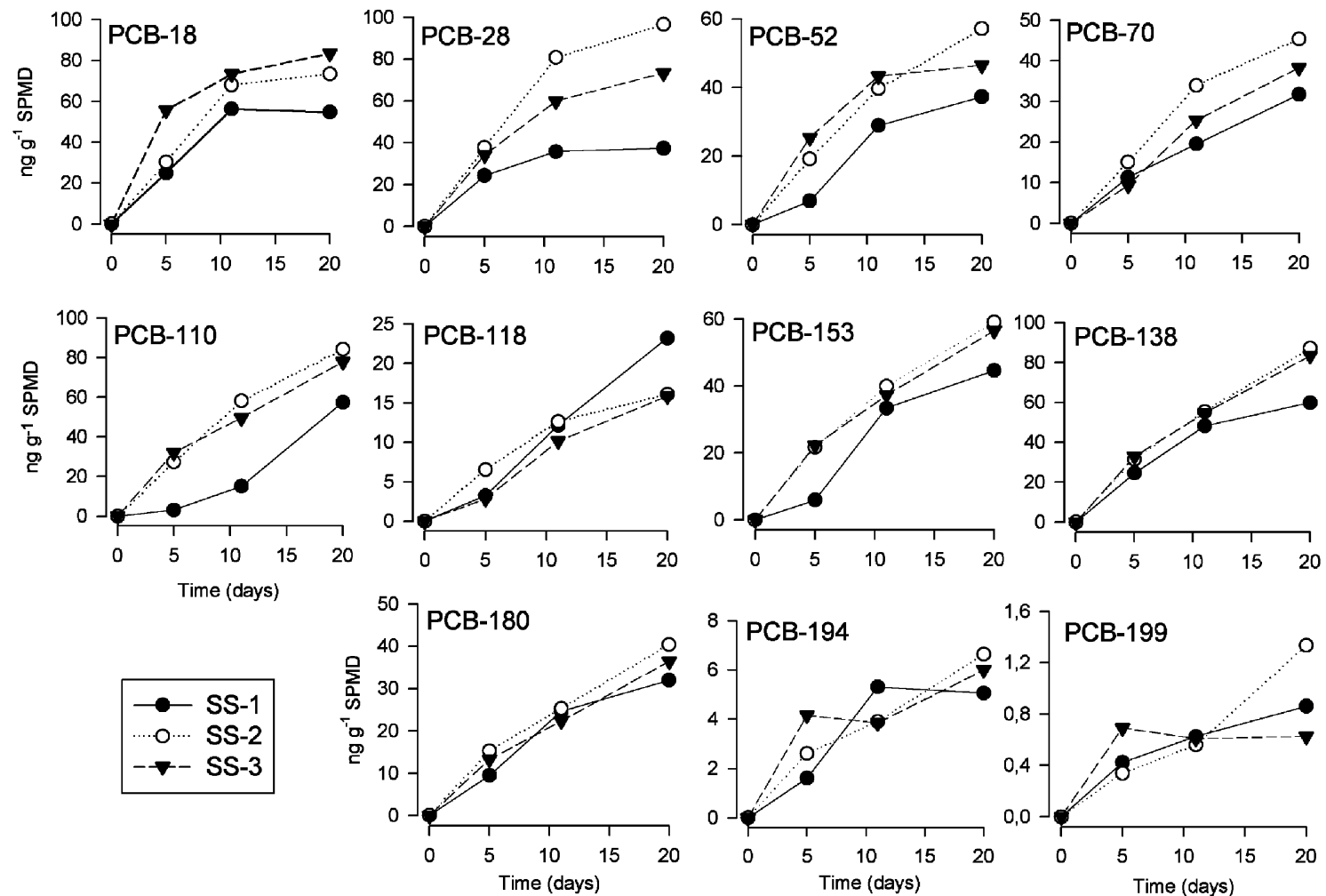

Fig. 5 Uptake rates of selected PCB congeners by SPMDs exposed for 5, 11 and $20 \mathrm{~d}$ in the Tajo River.

compounds (PRCs) - deuterated PAHs or ${ }^{13} \mathrm{C}$ stable isotopes of similar physicochemical properties to analytes of interestinto the SPMD prior to deploying it in the field. An extensive review on the theoretical basis and experimental evidence of the PRC approach has been reported by Huckins et al. ${ }^{16}$ However, the use of PRCs can add further complications to the chemical analysis, especially when SPMDs are routinely used as environmental monitoring tools or when a wide range of HOCs - more PRCs are needed in consequence - are ana- lysed. Moreover, Luellen and Shea ${ }^{20}$ compared the sampling rates of PAHs and related hydrocarbons in laboratory and field conditions using PRCs, and no significant variations were found between the PRC-corrected $R_{\mathrm{S}}$ and PRC-uncorrected $R_{\mathrm{S}}$. An alternative approach to minimize the effect of biofouling on the SPMD sampling rate can be to shorten the exposure time of the SPMD in the field. In moderately polluted environments, a short time of exposure (1 week) may be sufficient to sequester quantifiable amounts of HOCs. ${ }^{20,34}$ Furthermore,

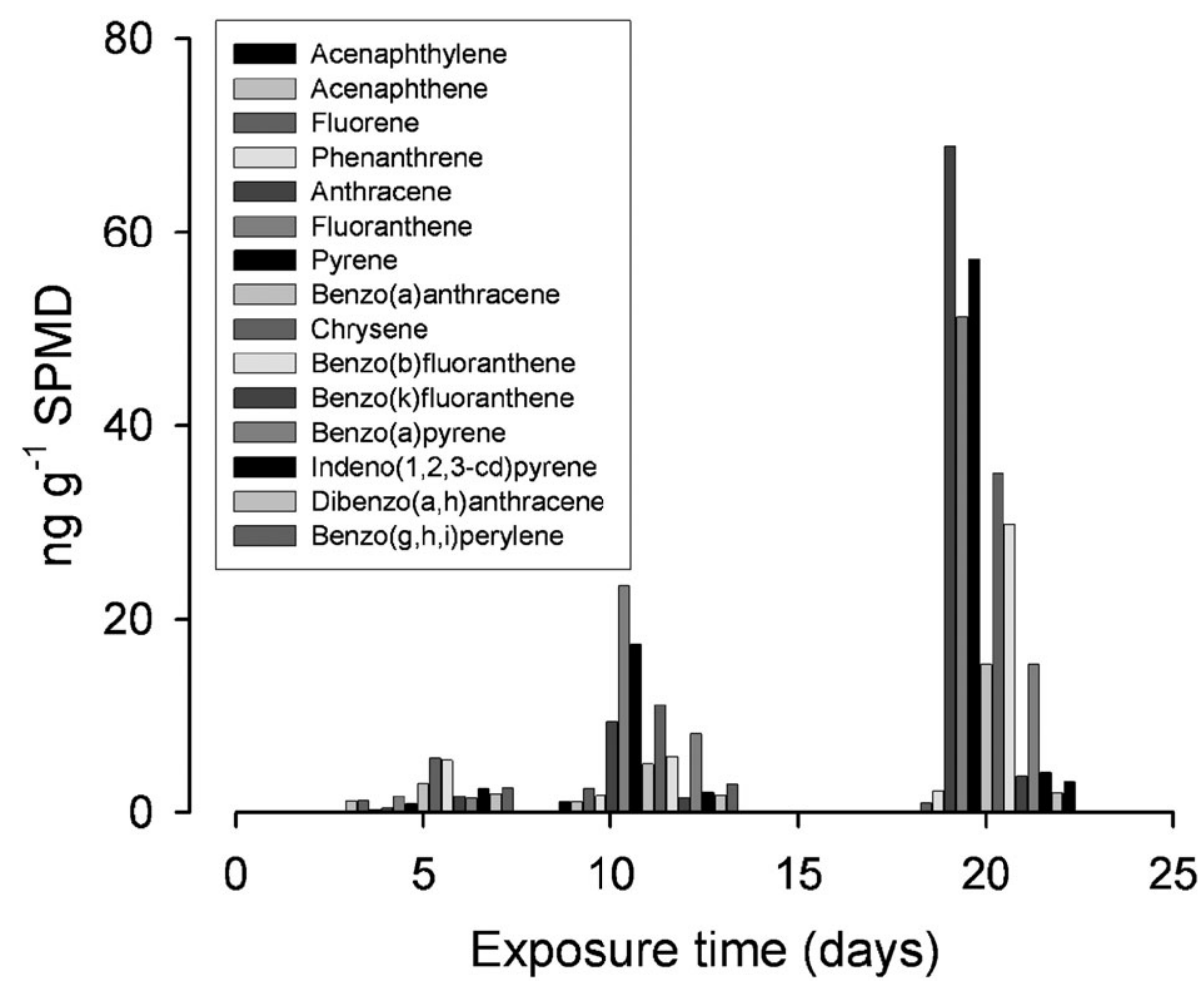

Fig. 6 Time-dependent increase of individual PAH concentrations in SPMDs deployed at sampling site 1 (SS-1, see Fig. 1). 
experimental evidence has shown that to assume linear uptake for several HOCs (e.g., PAHs with $\log K_{\mathrm{OW}}<4.5$ ) during long periods of SPMD deployment $(28-30 \mathrm{~d})$ and to use linear kinetic models for estimating water concentrations is not totally valid. ${ }^{17,20}$ We decided therefore to use concentrations measured in SPMDs exposed for $5 \mathrm{~d}$ to estimate water HOC concentrations because of less biofouling on the SPMDs.

Concentrations of dissolved organochlorine pesticides and PAHs were estimated using eqn. (2) and taking the experimental sampling rates for PAHs from Huckins et al., ${ }^{15}$ and for organochlorine pesticides from Huckins et al. ${ }^{26}$ The $R_{\mathrm{S}}$ used for calculations were those estimated at $26{ }^{\circ} \mathrm{C}$ because water temperature in our study area varied between 22.7 and $25.5^{\circ} \mathrm{C}$ throughout the sampling period. Estimation of water concentrations of PCBs was not performed because of lack of literature data for experimental sampling rates of PCBs at temperatures higher than $20^{\circ} \mathrm{C}$.

The estimated concentrations $\left(\mathrm{ng} \mathrm{L}^{-1}\right)$ of organochlorine pesticides in the Tajo River ranged from 0.80 to 2.48 for HCB, 1.30 to 11.5 for $\gamma-\mathrm{HCH}, 0.61$ to 2.02 for $4,4^{\prime}$-DDT, and 6.89 to 11.59 for $4,4^{\prime}$-DDE. In general, these water concentrations were high in comparison with those estimated for other polluted fluvial systems. Ellis et al. ${ }^{29}$ reported water concentrations of $\gamma-\mathrm{HCH}$ in the upper Mississippi River that varied from 0.05 to $0.3 \mathrm{ng} \mathrm{L}^{-1}$. The concentrations of $4,4^{\prime}$-DDE and $4,4^{\prime}$ DDT in the SPMDs exposed in the Tajo River were in the same range of variation as those estimated by Petty et al. ${ }^{28}\left(4,4^{\prime}\right.$ $\mathrm{DDE}=0.26-18 \mathrm{ng} \mathrm{L}{ }^{-1} ; 4,4^{\prime}$-DDT $=1.2-7.7 \mathrm{ng} \mathrm{L}^{-1}$ ) in SPMDs exposed in streams receiving irrigation drainwater (SW Oklahoma, USA). Similarly, the water HCB concentrations estimated in our study were similar to those $(\mathrm{HCB}=$ 0.021-6.86 $\mathrm{ng} \mathrm{L}^{-1}$ ) reported in the monitoring study by Verweij et al. $^{30}$, however the concentration range for $4,4^{\prime}$ DDE (0.018-0.189 $\left.\mathrm{ng} \mathrm{L}^{-1}\right)$ was much lower than that estimated for the Tajo River. Petty et al. ${ }^{13}$ also reported water concentrations of HCB $\left(0.31 \mathrm{ng} \mathrm{L}^{-1}\right)$ and 4,4'-DDE $(0.89 \mathrm{ng}$ $\mathrm{L}^{-1}$ ) in a polluted environment (the effluent of the International Wastewater Treatment Plant which empties into the Santa Cruz River, USA), which were lower than the minimum concentrations estimated for the Tajo River.

The concentrations of organochlorines estimated from SPMDs exposed in the Tajo River were in the same ranges of variation as those measured in other Spanish rivers (3.4-54 ng $\mathrm{L}^{-1}$ for the sum of $\alpha-$ and $\gamma-\mathrm{HCH} ; 3.1-50$ for the sum of $4,4^{\prime}$-DDT and 4,4'-DDE). ${ }^{24,25}$ These are concentrations that should be considered as high even compared with concentrations generally measured in polluted rivers such as the Pearl River (South China), where an input of fresh DDT occurs (0.13-0.94 ng L ${ }^{-1}$ for the sum of 4,4'-DDT and 4,4'-DDE, and 13.28-39.46 ng L ${ }^{-1}$ for the sum of $\alpha$ - and $\left.\gamma-\mathrm{HCH}\right){ }^{35}$

The estimated concentrations of total PAHs in the three sampling sites varied from 12.05 to $26.75 \mathrm{ng} \mathrm{L}^{-1}$. Although the thermoelectric power plant situated near the SS- 1 site could be a potential source of $\mathrm{PAHs}$, the estimated concentrations at this site were lower $\left(13.2 \mathrm{ng} \mathrm{L}^{-1}\right)$ than concentrations commonly found in aquatic systems contaminated by these HOCs. Moring and Rose ${ }^{36}$ estimated total PAH concentrations between 34.3 and $66.3 \mathrm{ng} \mathrm{L}^{-1}$ in SPMDs exposed for 30-31 d in the Trinity River basin (Texas, USA). Likewise, Stuer-Lauridsen and Kjolholt ${ }^{34}$ estimated total PAH concentrations varying between 70 and $390 \mathrm{ng} \mathrm{L}^{-1}$ in wastewater from concentrations in SPMDs exposed for $6 \mathrm{~d}$.

\section{Considerations on field SPMD kinetic studies}

Determination of SPMD-based water concentrations of HOCs has been accepted as a rapid and cost effective method with respect to the sampling and analysis of high volumes of water. Water concentrations of HOCs estimated from SPMDs have been compared with direct measurements in the water column using conventional sampling and analytical methods. ${ }^{11,34}$ Although differences have been found between the methods (i.e., SPMD and analysis of water), especially depending on the analyte of interest, these vary on the same order of magnitude. One of the main factors contributing to these variations could be the nature of the sampling. SPMD passively accumulates HOCs and it needs an exposure time higher than $24 \mathrm{~h}$ to sequester measurable amounts of analytes (integrating pollution system),${ }^{3}$ while HOC concentrations measured directly in water correspond to the precise instant of water sampling. Temporal variation of HOC concentrations determined in SPMDs periodically recovered from water could be a desirable approach to identify episodic events of pollution. Furthermore, the biofouling on the outer surface of the SPMD can interfere in the estimation of water HOC concentrations. Our first consideration derived from the results is that shorter times of SPMD exposure ( $\sim 1$ week) are recommended to minimise the biofouling and to therefore accurately estimate dissolved HOC concentrations avoiding the use of PCRs. Considering the SPMDs exposed in the SS- 1 site where a linear uptake rate for total PAHs was observed (Fig. 4B), we compared the concentrations of these pollutants estimated from concentrations in SPMDs exposed for $5 \mathrm{~d}$ and those estimated from concentrations in SPMDs exposed for $11 \mathrm{~d}$. Estimated dissolved concentrations of PAHs were $13.2 \mathrm{ng} \mathrm{L}^{-1}$ when PAH concentrations in $5 \mathrm{~d}$-exposed SPMDs were used for analysis, whereas a concentration of $9.2 \mathrm{ng} \mathrm{L}^{-1}$ was obtained when 11 d-exposed SPMDs were considered for calculations. However, an independent measure of water concentration would be necessary to confirm this observation. Similarly, estimated concentrations of HCB, DDTs and $\gamma-\mathrm{HCH}$ from $5 \mathrm{~d}-$ and $20 \mathrm{~d}-\mathrm{ex}-$ posed SPMDs revealed similar results. Water concentrations of DDTs and $\gamma-\mathrm{HCH}$ from SPMDs exposed for $20 \mathrm{~d}$ were 7 to $45 \%$ lower than those derived from SPMDs exposed for $5 \mathrm{~d}$. This underestimation of dissolved HOC concentrations has already been suggested by Richardson et al. ${ }^{37}$ and Luellen and Shea $^{20}$ on the basis of SPMD uptake impedance derived from biofouling in the long time period of SPMD exposure.

A second consideration is related to the possibility of identifying point sources of HOCs, an important issue in environmental risk assessment protocols. Examination of SPMD uptake rates of certain pollutants under a field kinetic approach can aid in the determination of point sources of contamination. Pollutants such as PAHs can be eliminated from the SPMDs when water PAH concentrations decrease; ${ }^{32}$ the increase of these pollutants in the SPMDs as time of exposure increases (Figs. 4B and 6) could therefore indicate a local source for PAHs. This was observed in the SPMDs deployed in the SS-1 site respective to the SPMDs deployed in the other two sampling sites. The presence of a thermoelectric power station near the SS-1 site could account for this linear uptake rate of PAHs. On the other hand, contaminants with low $\log K_{\mathrm{Ow}}$ values such as $\mathrm{HCH}$ tend to reach equilibrium rapidly in SPMDs, and the examination of their field uptake rates could point out a local input for these organochlorine compounds.

Our final consideration on the use of SPMDs under a kinetic approach is related to the assessment of field exposure to HOCs by biota. The fact that SPMDs passively accumulate HOCs over time has led to the comparison of these sampling devices to biomonitors (e.g., mussels). Although several authors have evidenced a good relationship between SPMDs and mussels in terms of accumulation rates, ${ }^{9}$ others retain some reservations on their use as "surrogate biomonitors" due mainly to substantial differences in the concentrations of contaminants accumulated by SPMDs and mussels. ${ }^{10,11,37}$ Despite this discrepancy, SPMDs have been accepted as a valuable environmental sampling system for providing an indication of potentially bioavailable HOCs in aquatic ecosystems, and for assessing exposure to contaminants that are 
difficult to detect in fish tissues by chemical analysis. Contaminants such as PAHs are rapidly metabolised by the hepatic cytochrome P4501A enzymatic system, ${ }^{38}$ and the assessment of field exposure to PAHs based on their residue levels in tissues is a difficult task. However, a good correlation has been found between water PAH concentrations estimated from SPMDs and biliary PAH metabolites in the fish Cyprinus carpio caged in polluted environments. ${ }^{30}$ This field study encourages the possibility of using SPMD and selected biomarkers measured in biota for evaluating exposure to certain HOCs. Furthermore, if SPMDs truly reflect the concentrations of HOCs in aquatic organisms or, at least, the bioaccumulation process, then concentrations in SPMDs could be used for estimating the internal effect concentration. ${ }^{39}$ In this sense, the kinetic approach in the use of SPMDs might be important to examine the relationship between concentrations of bioavailable HOCs in biota and progressive biomarker responses leading to adverse effects.

\section{Acknowledgements}

We thank JN Huckins for his helpful comments on an early draft of the manuscript. This work was financed by a Marie Curie grant (MCFI-648) from the European Union (JCSH).

\section{References}

1 J. N. Huckins, M. W. Tubergen and G. K. Manuweera, Chemosphere, 1990, 20, 533.

2 A. Kot, B. Zabiegata and J. Namiesnik, Trends Anal. Chem., 2000, 19, 446.

3 Y. Lu, Z. Wang and J. N. Huckins, Aquat. Toxicol., 2002, 60 139.

4 J. D. Petty, J. N. Huckins, C. E. Orazio, J. A. Lebo, B. C. Poulton, R. W. Gale, C. S. Charbonneau and E. M. Kaiser, Environ. Sci. Technol., 1995, 29, 2561.

5 J. F. McCarthy, G. R. Southworth, K. D. Ham and J. A. Palmer, Environ. Toxicol. Chem., 2000, 19, 352.

6 G. S. Ellis, J. N. Huckins, C. E. Rostad, C. J. Schmitt, J. D. Petty and P. MacCarthy, Environ. Toxicol. Chem., 1995, 14, 1875.

7 C. S. Hofelt and D. Shea, Environ. Sci. Technol., 1997, 31, 154.

8 A. Granmo, R. Ekelund, M. Berggren, E. Brorström-Lundén and P. Bergqvist, Environ. Sci. Technol., 2000, 34, 3323.

9 C. S. Peven, A. D. Uhler and F. J. Querzoli, Environ. Toxicol. Chem., 1996, 15, 144.

10 B. J. Richardson, G. J. Zheng, E. S. C. Tse and P. K. S. Lam, Chemosphere, 2001, 45, 1201.

11 J. Axelman, K. Nae, C. Näs and D. Broman, Environ. Toxicol. Chem., 1999, 18, 2454.

12 D. Sabaliunas, J. R. Lazutka and I. Sabaliuniene, Environ. Pollut., 2000, 109, 251.

13 J. D. Petty, S. B. Jones, J. N. Huckins, W. L. Cranor, J. T. Parris, T. B. McTague and T. P. Boyle, Chemosphere, 2000, 41, 311.
14 J. N. Huckins, G. K. Manuweera, J. D. Petty, D. Mackay and J. A. Lebo, Environ. Sci. Technol., 1993, 27, 2489.

15 J. N. Huckins, J. D. Petty, C. E. Orazio, J. A. Lebo, R. C. Clark, V. L. Gibson, W. R. Gala and K. R. Echols, Environ. Sci. Technol., 1999, 33, 3918.

16 J. N. Huckins, J. D. Petty, J. A. Lebo, F. V. Almeida, K. Booij, D. A. Alvarez, W. L. Cranor, R. C. Clark and B. B. Mogensen, Environ. Sci. Technol., 2002, 36, 85.

17 C. S. Hofelt and D. Shea, Environ. Sci. Technol., 1997, 31, 154.

18 K. Booij, H. M. Sleiderink and F. Smedes, Environ. Toxicol. Chem., 1998, 17, 1236.

19 J. D. Petty, C. E. Orazio, J. N. Huckins, R. W. Gale, J. A. Lebo, J. C. Meadows, K. R. Echols and W. L. Cranor, J. Chromatogr., $A, 2000,879,83$.

20 D. R. Luellen and D. Shea, Environ. Sci. Technol., 2002, 36, 1791.

21 J. O. Grimalt, P. Fernandez, L. Berdie, R. M. Vilanova, J. Catalan, R. Psenner, R. Hofer, P. G. Appleby, B. O. Rosseland, L. Lien, J. C. Massabuau and R. W. Battarbee, Environ. Sci. Technol., 2001, 35, 2690.

22 A. Ribes, J. O. Grimalt and C. J. T. Garcia, J. Environ. Qual., 2003, 32, 977.

23 A. Ribes, J. O. Grimalt, C. J. Torres Garcia and E. Cuevas, Environ. Sci. Technol., 2002, 36, 1879.

24 L. R. Bordajandi, G. Gómez, M. A. Fernández, E. Abad, J. Rivera and M. J. González, Chemosphere, 2003, 53, 163.

25 M. Fernández, S. Cuesta, O. Jiménez, M. A. García, L. M. Hernández, M. L. Marina and M. J. González, Chemosphere, 2000, 41, 801 .

26 J. N. Huckins, J. D. Petty, H. F. Prest, R. C. Clark, D. A. Alvarez, C. E. Orazio, J. A. Lebo, W. L. Cranor and B. T. Johnson, A guide for the use of semipermeable membrane devices (SPMDs) as samplers of waterborne hydrophobic organic contaminants, API publication 4690, American Petroleum Institute, Washington, DC, 2002, pp. 1-192.

27 O. C. Amaral, R. Otero, J. O. Grimalt and J. Albaiges, Water Res., 1996, 30, 1876.

28 J. D. Petty, J. N. Huckins, D. B. Martin and T. G. Adornato, Chemosphere, 1995, 30, 1891.

29 G. S. Ellis, J. N. Huckins, C. E. Rostad, C. J. Schmitt, J. D. Petty and P. MacCarthy, Environ. Toxicol. Chem., 1995, 14, 1875.

30 F. Verweij, K. Booij, K. Satumalay, N. van der Molen and R. van der Oost, Chemosphere, 2004, 54, 1675.

31 K. R. Echols, R. W. Gale, T. R. Schwartz, J. N. Huckins, L. L. Williams, J. C. Meadows, D. Morse, J. D. Petty, C. E. Orazio and D. E. Tillitt, Environ. Sci. Technol., 2000, 34, 4095.

32 T. Baussant, S. Sanni, G. Jonsson, A. Skadsheim and J. F. Borseth, Environ. Toxicol. Chem., 2001, 20, 1175.

33 E. R. Bennett, T. L. Metcalfe and C. D. Metcalfe, Chemosphere, 1996, 33, 363.

34 F. Stuer-Lauridsen and J. Kjolholt, Water Res., 2000, 34, 3478.

35 X. Luo, B. Mai, Q. Yang, J. Fu, G. Sheng and Z. Wang, Mar. Pollut. Bull., 2004, 48, 1102.

36 J. B. Moring and D. R. Rose, Chemosphere, 1997, 34, 551.

37 B. J. Richardson, G. J. Zheng, E. S. C. Tse, S. B. Luca-Abbott, S. Y. M. Siu and P. K. S. Lam, Environ. Pollut., 2003, 122, 223.

38 J. J. White, R. E. Jung, C. J. Schmitt and D. E. Tillitt, Crit. Rev. Toxicol., 2000, 30, 347.

39 B. I. Escher and J. L. M. Hermens, Environ. Sci. Technol., 2002, 36, 4202. 